\title{
Philippe Willemart, À la découverte des sensations dans "La Prisonnière" de Marcel Proust
}

Geneviève Henrot Sostero

\section{(2) OpenEdition}

1 Journals

Édition électronique

URL : http://journals.openedition.org/studifrancesi/9328

DOI : 10.4000/studifrancesi.9328

ISSN : 2427-5856

Éditeur

Rosenberg \& Sellier

Édition imprimée

Date de publication : 1 juin 2008

Pagination : 221

ISSN : 0039-2944

\section{Référence électronique}

Geneviève Henrot Sostero, "Philippe Willemart, À la découverte des sensations dans "La Prisonnière" de Marcel Proust », Studi Francesi [En ligne], 154 (LII | I) | 2008, mis en ligne le 30 novembre 2015, consulté le 11 janvier 2021. URL : http://journals.openedition.org/studifrancesi/9328 ; DOI : https://doi.org/ $10.4000 /$ studifrancesi.9328

Ce document a été généré automatiquement le 11 janvier 2021.

\section{(c) (†) $\odot$}

Studi Francesi è distribuita con Licenza Creative Commons Attribuzione - Non commerciale - Non opere derivate 4.0 Internazionale. 


\title{
Philippe Willemart, À la découverte des sensations dans "La Prisonnière" de Marcel Proust
}

\author{
Geneviève Henrot Sostero
}

\section{RÉFÉRENCE}

PHILIPPE WILLEMART, À la découverte des sensations dans "La Prisonnière" de Marcel Proust, Paris, L'Harmattan, 2007, pp. 234.

1 Auteur de plusieurs ouvrages à la croisée entre génétique et psychanalyse, cet éminent proustien d'origine belge enseignant au Brésil (Université de São Paulo) ne dément pas le triangle de ses passions. Le critique de Au-delà de la psychanalyse: les arts de la littérature (L'Harmattan, 1998) et de Proust poète et psychanalyste (L'Harmattan, 1999) nous livre coup sur coup deux publications, toujours aux Presses de L'Harmattan Paris: Critique et génétique: pratiques et théorie (dont il est rendu compte sous ce titre) et le présent essai.

2 Deux parties inégalement balancées rassemblent respectivement onze chapitres de lectures de La Prisonnière et deux chapitres de considérations sur 'l'inexistant', sa logique et ses processus de création. Dans un va-et-vient herméneutique pédestre entre texte et manuscrits, chaque étape de lecture, fidèle au cours du récit comme aux talus du texte, observe combien l'analyse de l'angoisse et de la jalousie, de la perversion et de l'inversion, fournissent à l'écrivain le terreau de son art et justifient ses injections de pur imaginaire.

3 Le récit de La Prisonnière ricoche, comme on sait, sur sept matinées itératives, qui reproduisent le principe mis en lumière pour la première fois par le critique John Porter Houston à propos de $D u$ côté de chez Swann. L'analyse est menée ici pas à pas, reposant sur de longues citations (mais comment citer Proust brièvement?), jusqu'au terme de la troisième matinée. Ce cabotage textuel permet à l'auteur d'ausculter les 
littoraux du roman, d'en humer les effluves, d'en ouïr les cris de passion, d'en filer les sentiers de création: comment le héros perçoit-il et apprivoise-t-il le monde, lui «étrange humain qui vi[t] comme un hibou», et comment la narration de cette expérience acquiert-elle, au fil des manuscrits, une «unité qui s'ignore», ou logique naturelle d'un monde cohérent? (ch. I, «'L'Unité qui s'ignorait' dans les manuscrits de l'Ouverture»). Les tonalités affectives variables de ces perceptions, de l'angoisse à l'euphorie, permettent de concevoir un critère d'identification par lequel pourrait se démêler le jeu serré des 'voix narratives' multiples de la Recherche: «Qui pleure là? Qui rit ici?». L'un «se laisse jouer par l'archet» de l'autre, p. 58) (ch. II: «De l'angoisse du baiser au cercle magique de l'odeur»; ch. IX: «La disparition de l'angoisse au réveil. Fin de la deuxième journée»; ch. X: «La mélodie des marchands ambulants»). L'intrusion d'Albertine dans ce monde solipsiste engage une dialectique de compromis entre la sauvage liberté de la jeune fille et le rigoureux enfermement (sanitaire, carcéral) du Narrateur. L'A. demande ici à Lacan d'éclairer la construction du personnage d'Albertine (ch. III: «Le monde étrange de la jalousie»; ch. VII: «La mine de la jalousie»; ch. VIII: «La torture réciproque de l'amour»). Les lois de la création et de la pensée habitent parfois le plus banal échantillon: l'art de s'habiller de la duchesse de Guermantes inspire une conception originale de l'histoire de France en même temps qu'il fournit un miroir analogique aux lois de la création (ch. IV: «Au-delà des yeux du corps»). De même, la perversion n'est-elle pas digne d'étude en tant que manifestation de l'amour, et ne peut-elle servir à nourrir l'art en lui fournissant un objet de réflexion? (ch. V: «Des tendances et des goûts pervers reconquis par l'amour et par l'art»; ch. VI: «Un héros gomorrhéen»).

Quant au chapitre XI, il anticipe quelque peu sur la seconde partie, en tant qu'il touche aux sphères immatérielles de la fiction romanesque (ch. XI: «Mensonge, fiction et rêve»), et prépare, dans les deux derniers chapitres (qui constituent la seconde partie du livre), la détection «dans La Prisonnière [de] la logique de l'inexistant développée par Gottlobe Frege et articulée à la théorie psychanalytique par Jacques Lacan» (p. 11) (ch. I: «La logique de l'inexistant»; ch. II: «Les processus de création et l'inexistant»).

5 Une «Bibliographie» critique et sélective, un «Index des concepts» et un «Index des noms» complètent le volume. 